\title{
Research on the cooperative innovation mechanism of agricultural science and technology in Chongqing three gorges reservoir area based on supply-side reform
}

\author{
Lianming Zhao \\ Department of Business Management, Chongqing Business Vocational College, 401331, \\ Chongqing, China
}

Keywords: Supply side redraft; Chongqing three gorges; Agricultural technology; Collaborative innovation; mechanism

\begin{abstract}
Agriculture is the basic industry of our country, and the development of agriculture is both economic and political. In the era of the globalization of knowledge economy, innovation has become the source and power of economic growth of various countries in the world. At the same time, the agricultural development and agricultural economic growth were also rely on scientific and technological progress and scientific and technological innovation to improve the quality of agricultural products, improve agricultural production efficiency and realize the product differentiation development of competition as much as possible. At present, China's agricultural development is gradually agricultural economic development is in line with the rest of the world, the government is waning of agricultural trade barriers or disappear, in the agricultural development has entered the production leading the traditional agriculture to technology leading a new stage of modern agricultural transformation this crucial period, an urgent need to deepen and accelerate the reform of agricultural scientific research system, adjusting and optimizing our country agricultural production and rural economic structure, transformation of the mode of agricultural economic growth from extensive management to intensive management, improve the quality of agricultural economic growth and economic efficiency, to accelerate the development of agricultural production the latter quantitative agricultural production, ensure national food security, ecological security and farmers' income. Therefore, agricultural development has raised higher requirements for agricultural scientific and technological progress and agricultural science and technology support.
\end{abstract}

\section{Introduction}

The innovation of agricultural science and technology is characterized by the use or recognition of agricultural scientific research results. From this perspective, agricultural science and technology innovation can be regarded as a whole and process. Therefore, in this paper, the author studies on agricultural science and technology innovation is in the balance of its concept and connotation of broad sense and narrow sense at the same time, the research focuses on up the whole grasp the connotation of agricultural scientific and technological innovation, the overall research to promote the dynamic mechanism of agricultural scientific and technological innovation, Chongqing three gorges reservoir area in this paper is not specifically about agricultural science and technology innovation process specific to do meticulous division, but the agricultural science and technology research and development, promotion and application are unified to the agricultural science and technology innovation in the system as a whole. Our main research goal is to explore the dynamic driving forces for Chongqing three gorges reservoir area, research, directly or indirectly ACTS on the agricultural science and technology innovation main body and produce agricultural science and technology innovation behavior way of motivation mechanism, function and its effect on the dynamic relationship between various factors and to focus on the influence factors to promote the development of agricultural science and technology innovation, focus on innovation main body of the intention and its influencing factors, can promote the main body of agricultural scientific and technological innovation driven force. It is necessary to explain that the dynamic factors that directly promote the 
behavior of agricultural science and technology innovation are the core content of the research on agricultural science and technology innovation.

\section{Agricultural innovation status}

Agricultural science and technology innovation process includes the exploration process, agricultural knowledge transfer process and the interaction between innovators and user process, this process and the degree of the diversity, complexity, the changes of natural conditions and biological characteristics are closely linked, the agricultural science and technology innovation industry hides a lot of uncertain factors, agricultural science and technology innovation to produce risk, long cycle and the opportunity cost is high, it is significantly different from other innovation in the field of agricultural science and technology innovation aspects. The uncertainty is specific performance in: science and technology innovation personnel to observe and explore the grasp of the various factors of production variables, the development direction of innovation and it's could eventually form the results of the uncertainty; Whether the reframe of production elements under the constraint of various conditions of nature is unpredicted or destroyed; Agricultural science and technology innovation achievements will be market demand by farmers' inspection, fully reflects the demand of the market, to anticipate the future existence which is to be able to play a role in agricultural science and technology and in a certain interest will be selected for production and price is for there is uncertainty or procurement; In the process of promoting innovation, due to different factors such as regional, land quality, climate water conservancy conditions and farmers' quality, there is also great uncertainty about the results of the transformation of results.

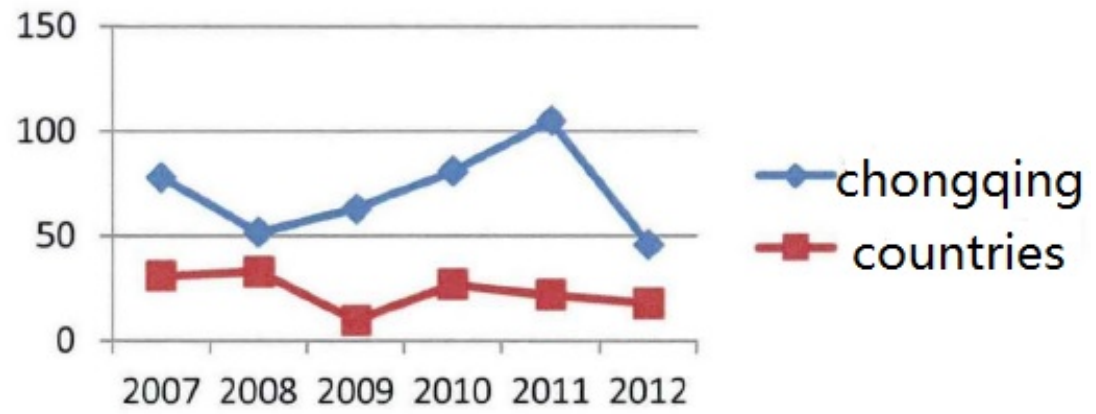

Fig. 1 national and Chongqing spark project

Although different countries have different backgrounds, systems and systems in agricultural ecological conditions and agricultural economic development, they are more similar or similar in advancing agricultural science and technology innovation. The promotion and application of agricultural science and technology innovation is different from industrial technology products, is highly vulnerable to the influence of different regional environment and restriction, an agricultural technology innovation must also be in accordance with the particular season and the growth of crop growth cycle to complete, and because crop varieties to adapt to the characteristics of a particular area, such as determines an agricultural technology popularization and application of regional specificity. Regional is the most essential characteristic of agricultural science and technology innovation, and the situation of agricultural economic development in different regions needs different agricultural scientific and technological innovation to satisfy.

Table 1 2012-2015 investment intensity of agricultural R\&D in Chongqing

\begin{tabular}{ccccc}
\hline Project/year & 2012 & 2013 & 2014 & 2015 \\
\hline Expenditure for agricultural R\&D expenditure & 5006 & 6480 & 7473 & 11603 \\
(ten thousand yuan) & & & & \\
Gross agricultural output (one hundred million yuan) & 720.1 & 787.8 & 841.4 & 858.2 \\
R\&D expenditure/agricultural GDP(\%) & 0.07 & 0.08 & 0.09 & 0.14 \\
\hline
\end{tabular}

\section{Literature References}


The innovation of agricultural science and technology is an inexhaustible driving force for agricultural economic development. Adam Smith made a similar point in the wealth of nations. Agricultural science and technology innovation is transformed into real productivity by materializing the factors of productivity. Agricultural science and technology innovation can improve the laborers, labor materials and labor object, etc. The combination of various factors of production ability and level, make a marked change all the factors of production, greatly improve the level of productivity, and accelerate the development of productivity in the countryside. Agricultural science and technology and laborer organic fusion, prompting the ability, intelligence and culture quality of laborer significantly improved, so as to reduce labor intensity and to lengthen working hours, improve labor efficiency. Agricultural science and technology innovation materialized labor materials, production tools, can push data transformation, perfect labor, labor means more modern, it mainly includes the improvement of agricultural labor tools to upgrade and provide a new means of production. The development of agricultural science and technology causes the labor object to change fundamentally, which can promote the change of agricultural labor object and broaden the utilization range of agricultural resources. Agricultural science and technology innovation of farming and animal husbandry major role mainly in the form of materialized: fine varieties, such as rice, wheat, single output increased significantly and good varieties of all related; Use the formula to apply fertilizer to the critical point of application. Irrigation water, such as agricultural water-saving technology; Pesticides are used to control pests and diseases; The surface film, such as the membrane covering cultivation technology system; The development of plastic film sheds, such as efficient and energy-saving sunlight greenhouse; Technology of paddy rice seedling and seedling. Agricultural science and technology innovation plays a certain role in the growth of animal husbandry, which is mainly reflected in the higher proportion of the overall contribution of scientific and technological progress to the increase of meat production. It plays a direct and indirect role in feeding technology, epidemic prevention and control, variety improvement, plastic mold heating sheds and breeding technology of pigs.

Scientific and reasonable performance evaluation plays an important guiding role in the collaborative innovation of agricultural science and technology, which is very important for enhancing the vitality of innovation. With innovative quality, support the industry development and actual effect as the guidance, to improve the original innovation ability and meet the needs of industrial strategy and major special as an important standard of evaluating the ability of science and technology, to establish scientific evaluation system. Tough should not only look at technical support industry development, also want to measure the innovation team building in soft data, guide the researchers took the initiative to participate in collaborative innovation, guide the interdisciplinary collaborative innovation team always around Chongqing characteristic of modern agriculture and industry innovation and development goal. To establish results of quality, efficiency as the main basis of cooperative innovation performance evaluation standard, the status of the research into realistic productivity and efficiency in the field of production as important basis of the performance evaluation incentive more scientific and technical personnel to carry out the deep cooperation. Different kinds of collaborative innovation performance evaluation should be different. Collaborative innovation of agricultural scientific research leading projects, in addition to evaluate from the academic value, must also be emphasized to solve key industrial generic technology problems and meet the demand of industry development to evaluate the guidance, the evaluation results as the important basis for project support. The collaborative innovation projects, leading to the enterprise should be more from the actual support effect to promote the development of industry, to see if really realize the achievement industrialization and to solve the actual problem. At the same time, we will combine the performance of major scientific research tasks and innovation teams, assess the output and influence of innovation teams, and pay attention to the spirit of innovation teams.

\section{Summary}


Profit distribution not only refers to the explicit income distribution through the technical cooperation between the subjects, but also the implicit benefit of intellectual property generated during the cooperation process. The rationality of the distribution of interests of all parties in the collaborative innovation of industry-university-research and research depends on the values of all parties, and it also depends on the credibility of the parties, which is difficult to define quantitatively. It may be easier to agree on an agreement at the beginning, but it will be unpleasant when the fruit is turned into a product that delivers economic benefits. In addition to the government's guiding policies on collaborative innovation, to effectively advance the collaborative innovation of agricultural science and technology, we must face up to the differences in the interests of participating parties. Innovation system of synergies not because innovation main body of the differences in the interests of all parties and generated automatically, it needs to protect agricultural science and technology synergy by interests mechanism innovation, the balance of the interests of all parties, so as to realize win-win between innovation subjects. It is critical that all parties should be defined in the agreement the respective range of interests and responsibilities border, especially in scientific research, enterprises, colleges and universities should be fully considered the interests of the parties, such as way of interest allocation in advance to make clear rules, forming reasonable benefit sharing mechanism, enables the units and individuals involved in collaborative innovation reasonably share the benefits of research achievement, embody research linked to individual contributions, interest allocation and the allocation of resources, solidarity, pooling strength, inspire enthusiasm, initiative and creativity of the participants. In the long term, it is necessary to highlight the value of knowledge capital and explore the interest distribution mechanism of technology investment. In practice will begin at a discount to buy into the elements of all parties and make scientific research institutions to obtain corresponding equity, so they can with the identity of the shareholders in the enterprise decision-making, share the profits, risks and making it diligently for cooperative enterprise research and development services for a long time. In addition, collaborative innovation parties should set up a win-win cooperation concept. In cooperation, we should make decisions based on the global interests rather than on the short duration. Considering their own interests and interests of the other party; We should consider the immediate interests and pursue long-term interests. Both economic interests and cooperative friendship are more cherished. If necessary, we can "step back" and work together effectively.

\section{Acknowledgements}

This paper is supported by the Humanities and Social Sciences Project of Chongqing Education Committee. (Project Name: Research on Cooperative Innovation Mechanism of Agricultural Science and Technology in Chongqing based on the Perspective of Supply-side reform. Project No. 16SKGH265. ) This paper is the research result of the Science and Technology Project of Chongqing Education Committee. (Project Name: Research on the Cooperative Innovation Mechanism of Agricultural Science and Technology in the Three Gorges Reservoir area of Chongqing based on Supply-side Reform. Project No. KJ1604201.)

\section{References}

[1] Chen shu-xia. Structure and measurement of agricultural industrial cluster value chain system -taking linan pecan industry as an example [D]. Zhejiang agriculture and forestry university, 2012(6) .(In Chinese)

[2] Zhu jingli. Research on agricultural supply chain cluster [D]. Shandong university of technology, 2009(3). (In Chinese)

[3] Yang lijun. Research on the development pattern of characteristic agricultural industrial clusters -- taking henan province as an example [J]. Anhui agricultural science, 2013(5): 35-46. (In Chinese) 
[4] Zhao xia, wu fangwei, zhang jinhua. Spatial configuration model of optimization and upgrading of agricultural industrial cluster: supply chain management perspective [J]. Financial research, 2017(8): 89-92. (In Chinese)

[5] Wei longbao, li jing. Analysis on the influence of cooperative relationship between agricultural industrial cluster subjects on the income of farmers and related enterprises -- taking anhui province as an example [J]. Jiangxi university of finance and economics, 2015 (1): 67-69. (In Chinese).

[6] Li jing, jie xiao wen. Research on agricultural industrial cluster model based on diamond model [J]. Journal of lanzhou university, 2014(3):114-117. (In Chinese). 